\title{
Microarray estimation of genomic inter-strain variability in the genus Ectocarpus (Phaeophyceae)
}

\author{
Simon M Dittami ${ }^{1,2,3}$, Caroline Proux ${ }^{4}$, Sylvie Rousvoal ${ }^{1,2}$, Akira F Peters ${ }^{5,6}$, J Mark Cock ${ }^{1,2}$, Jean-Yves Coppée ${ }^{4}$,
} Catherine Boyen ${ }^{1,2}$, Thierry Tonon ${ }^{1,2^{*}}$

\begin{abstract}
Background: Brown algae of the genus Ectocarpus exhibit high levels of genetic diversity and variability in morphological and physiological characteristics. With the establishment of E. siliculosus as a model and the availability of a complete genome sequence, it is now of interest to analyze variability among different species, ecotypes, and strains of the genus Ectocarpus both at the genome and the transcriptome level.
\end{abstract}

Results: We used an E. siliculosus gene expression microarray based on EST sequences from the genomesequenced strain (reference strain) to carry out comparative genome hybridizations for five Ectocarpus strains: four E. siliculosus isolates (the male genome strain, a female strain used for outcrosses with the genome strain, a strain isolated from freshwater, and a highly copper-tolerant strain), as well as one strain of the sister species E. fasciculatus. Our results revealed significant genomic differences between ecotypes of the same species, and enable the selection of conserved probes for future microarray experiments with these strains. In the two closely related strains (a male and a female strain used for crosses), genomic differences were also detected, but concentrated in two smaller genomic regions, one of which corresponds to a viral insertion site.

Conclusion: The high variability between strains supports the concept of E. siliculosus as a complex of cryptic species. Moreover, our data suggest that several parts of the Ectocarpus genome may have evolved at different rates: high variability was detected particularly in transposable elements and fucoxanthin chlorophyll a/c binding proteins.

\section{Background}

Brown algae are multicellular and almost exclusively marine organisms, which live along the coastlines of all continents. They are economically important [1] as a food product mainly in Asian countries, as animal food or fertilizer due to their high mineral and trace element contents, and as a source of polysaccharides such as alginates. More recently, additional uses, e.g. as a resource for drug development, as a biofuel resource, or as nutrient- and heavy metal uptake systems, have also been explored (see [2] for a review). Brown algae are ecologically significant as they form the dominant vegetation in the intertidal and subtidal zone of rocky

\footnotetext{
* Correspondence: tonon@sb-roscoff.fr

'UPMC Univ Paris 6, UMR 7139 Marine Plants and Biomolecules, Station Biologique, 29680 Roscoff, France

Full list of author information is available at the end of the article
}

shores; large species, such as giant kelps, provide habitats for many other organisms [2]. Being part of the heterokont lineage within the chromalveolate kingdom, brown algae have evolved independently from other multicellular eukaryotes, including land plants and red and green algae [3]. In spite of their importance, there are still many gaps in our knowledge about brown algae, such as the mechanisms involved in their development, their complex life cycles [4], and their responses to stress.

Among brown algae, Ectocarpus siliculosus has a long history of research [5], and was chosen as a genetic model [6] due to its small genome and its short life cycle. Its genome has recently been sequenced and annotated, and is the first available for any seaweed [7]. Until recently, it was generally accepted that the genus Ectocarpus included only two species, E. siliculosus and 
E. fasciculatus. The cosmopolitan E. siliculosus, however, shows a particularly high level of genetic diversity and probably contains several cryptic species; one of which has been taxonomically re-instated as E. crouaniorum [8-10].

In addition to this genetic diversity, Ectocarpus also exhibits a considerable degree of physiological plasticity, and some strains have been isolated from quite extreme physiological conditions, such as freshwater $[11,12]$ and a site that was severely polluted with heavy metals [13]. Such ecotypes constitute a valuable resource for the study of adaptation to different environments, as demonstrated by numerous reports for terrestrial plants, comparing e.g. Arabidopsis thaliana and the closely related halophyte Thellungiella salsuginea (reviewed in [14]). In Ectocarpus a similar comparison of two strains has been performed on a proteomic level, highlighting for instance the importance of a photosystem II Mnstabilizing protein and of a fucoxanthin chlorophyll a/c binding protein (FCP) during the adaptation to high levels of copper [13].

Microarray experiments could provide valuable insights into the biology of different ecotypes as well as into their specific adaptations, as they allow transcript abundances to be assayed for a large number of genes at a comparatively low cost. Currently, an expression array based on the genome-sequenced strain of E. siliculosus is available, which comprises 68,270 probes for 17,119 sequences, including 8,165 contigs and 8,874 singletons from several expressed sequence tag (EST) libraries [15]. However, considering the present uncertainty with respect to the presence of cryptic species within E. siliculosus and physiological differences between the strains, caution needs to be taken when using this array for other strains [16]: cross-hybridization, alternative splicing, and sequence divergence may significantly decrease the accuracy of such experiments.

Comparative genome hybridization ( $\mathrm{CGH}$ ) experiments, using expression arrays and genomic DNA (gDNA), have been used as a means of assessing the suitability of microarrays for cross-strain and/or crossspecies hybridizations. This was first demonstrated by Ranz et al. [17] for two closely related species of Drosophila, and has been successfully applied in land plants $[18,19]$. The results from such CGH experiments can be used to mask probes with high inter-strain and interspecies variability, thus increasing the accuracy of expression analyses carried out with alternative strains or species. Moreover, in spite of the limitations imposed by the use of gene expression arrays, cross-species hybridizations may also yield information on rapidly evolving or highly conserved gene sets. For example, in a recent analysis of two related species of soybean, the highest degree of conservation was observed for genes involved in basic metabolic processes such as photosynthesis, while a high degree of variability was observed for signal transduction genes such as transcription factors [20].

In this study, we used a similar approach. CGH experiments were performed with five different strains of Ectocarpus and three objectives in mind: 1) to estimate the genomic variability between strains; 2 ) to facilitate future cross-strain gene expression experiments by enabling the masking of divergent probes; and 3) to identify possible rapidly evolving gene families and/or genomic regions.

\section{Results and Discussion}

\section{Selection of strains}

Five Ectocarpus strains from different origins (Table 1) were selected based both on their phenotypic characteristivcs and on their classification within the taxonomic clades defined by Stache-Crain et al. [8]. In our study, the species name E. siliculosus is used to refer collectively to clades $1-4$ of this phylogeny.

Strain 1 is the genome-sequenced strain of E. siliculosus. ESTs produced for this strain were used for the design of the gene expression array. This strain falls into clade 1c of the Stache-Crain et al. [8] phylogeny, and served as a reference strain for all hybridizations. Strain 2 falls into the same clade [9] (Table 1), and is known to be cross-fertile with strain 1 , but exhibits a high degree of genetic polymorphism. Strains 1 and 2 were used to construct the recently published genetic map for Ectocarpus [21]. Strain 3 was chosen as it is the only well documented isolate from freshwater [11,12]. Its internal transcribed spacer (ITS) 1 region, which was sequenced in this study, revealed that it falls into clade 2 d. Strain 4, which belongs to clade 1a, was of particular interest due to its high tolerance to copper and also because of the available proteomic data [13]. Finally, strain 5 belongs to a different species (E. fasciculatus), and was chosen as an outgroup to assist the interpretation of the degrees of variance observed within the different E. siliculosus strains. The relative genetic distances between the examined strains, based on an alignment of the ITS1 region, are displayed in Figure 1.

\section{Reliability of the CGH experiments}

In order to assess the reproducibility of our $\mathrm{CGH}$ experiments, a reference-reference hybridization was carried out with gDNA from two independent cultures of strain 1 (labeled with $\mathrm{Cy} 3$ and $\mathrm{Cy} 5$ respectively). The results of this experiment demonstrated that only 166 of the 68,270 probes $(0.24 \%)$ exhibited log2-differences in signal intensity $>1$ (i.e. $>2$-fold change). A more detailed examination revealed that 90 of these 166 probes (54\%) were not associated to a genomic supercontig (Sctg). Overall this was the case for 2,676 probes 
Table 1 Accession numbers, origin, and description of strains used in our experiments

\begin{tabular}{|c|c|c|c|c|c|c|c|}
\hline $\begin{array}{l}\text { Strain } \\
\text { number in } \\
\text { this paper }\end{array}$ & Strain characteristics & $\begin{array}{l}\text { Number in } \\
\text { Ectocarpus strain } \\
\text { collection at SBR }\end{array}$ & $\begin{array}{l}\text { CCAP } \\
\text { accession }\end{array}$ & Origin & Species & $\begin{array}{l}\text { Ectocarpus } \\
\text { clade }\end{array}$ & $\begin{array}{l}\text { ITS1 } \\
\text { sequence } \\
\text { accession }\end{array}$ \\
\hline 1 & $\begin{array}{l}\text { Genome-sequenced strain, male partheno- } \\
\text { sporophyte from fully marine environment }\end{array}$ & Ec 32 & $1310 / 4$ & $\begin{array}{l}\text { San Juan de } \\
\text { Marcona, } \\
\text { Peru }\end{array}$ & E. siliculosus & 1c & AJ550048 \\
\hline 2 & $\begin{array}{l}\text { Female partheno-sporophyte, sexually } \\
\text { compatible with strain } 1 \text {, from fully marine } \\
\text { environment (subtidal } 3 \mathrm{~m} \text { ) }\end{array}$ & Ec 568 & 1310/334 & Arica, Chile & E. siliculosus & 1c & FN564446 \\
\hline 3 & $\begin{array}{l}\text { Freshwater strain, unknown sex or life-history } \\
\text { stage }\end{array}$ & Ec 371 & 1310/196 & $\begin{array}{l}\text { Hopkins River } \\
\text { Falls, Victoria, } \\
\text { Australia }\end{array}$ & E. siliculosus & $2 d$ & GQ351370 \\
\hline 4 & $\begin{array}{l}\text { Copper-tolerant strain, unknown sex or life- } \\
\text { history stage }\end{array}$ & Ec 524 & $1310 / 333$ & $\begin{array}{l}\text { Palito La } \\
\text { Boca, } \\
\text { Chañaral, } \\
\text { Chile }\end{array}$ & E. siliculosus & $1 a$ & FN564444 \\
\hline 5 & $\begin{array}{l}\text { Outgroup, from fully marine environment } \\
\text { (upper subtidal, epiphytic on Himanthalia), } \\
\text { unknown sex or life-history stage }\end{array}$ & Ec 395 & - & $\begin{array}{l}\text { Roscoff, } \\
\text { France }\end{array}$ & E. fasciculatus & $5 b$ & FN564441 \\
\hline
\end{tabular}

Ectocarpus clade numbers $[54,9,10]$ correspond to a previous phylogenetic analysis [8]. SBR $=$ Station Biologique de Roscoff, CCAP $=$ Culture Collection of Algae and Protozoa, Dunstaffnage, Scotland http://www.ccap.ac.uk/.

(3.9\%, see Methods for additional details), indicating that a part of these sequences might correspond to contamination in the ESTs and/or to low complexity regions that are difficult to sequence.

The reference-reference experiment therefore demonstrated a high degree of technical reproducibility in

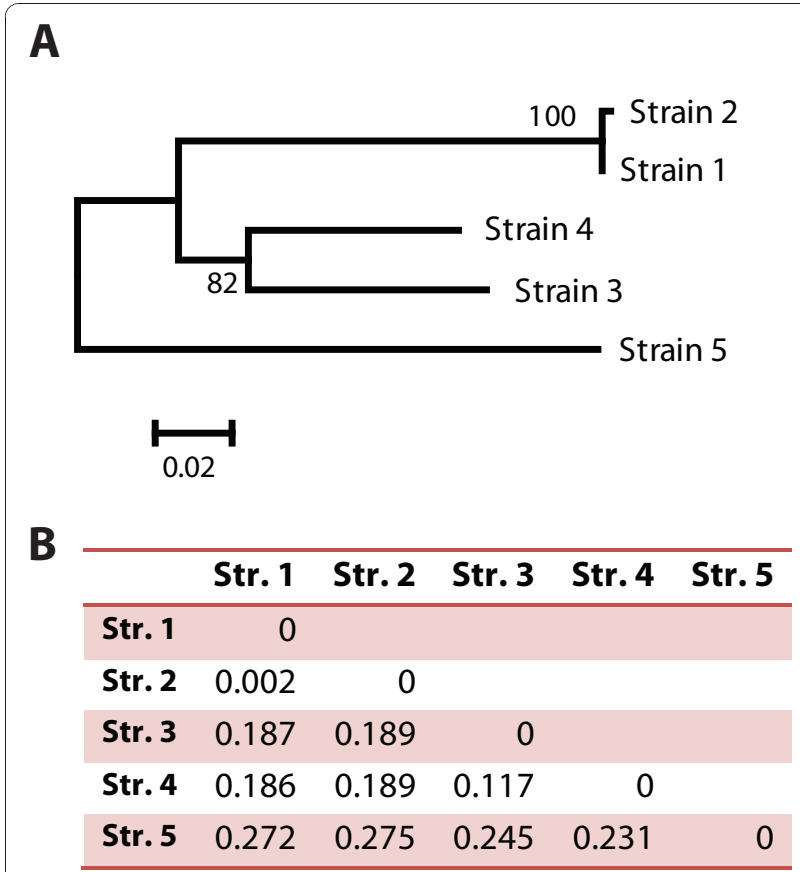

Figure 1 Phylogenetic relationships between the five Ectocarpus strains examined in this study (Str. 1-5) inferred from the ITS1 region. A) Neighbor-joining tree (BIONJ, default parameters) of the ITS regions of strain 1-5; 100 bootstrap replicates. B) Corresponding distance matrix for the tree in panel A. microarray experiments employing gDNA. One reason for this can be found in the distribution of absolute signal intensities obtained with gDNA, compared to cDNA (Figure 2). Genomic DNA-based CGH experiments result in signal intensity distributions with a maximum at medium signal intensities and thus high signal to noise ratios, because all genes are present in similar copy numbers. In contrast, cDNA or RNA experiments need to accommodate large differences in transcript

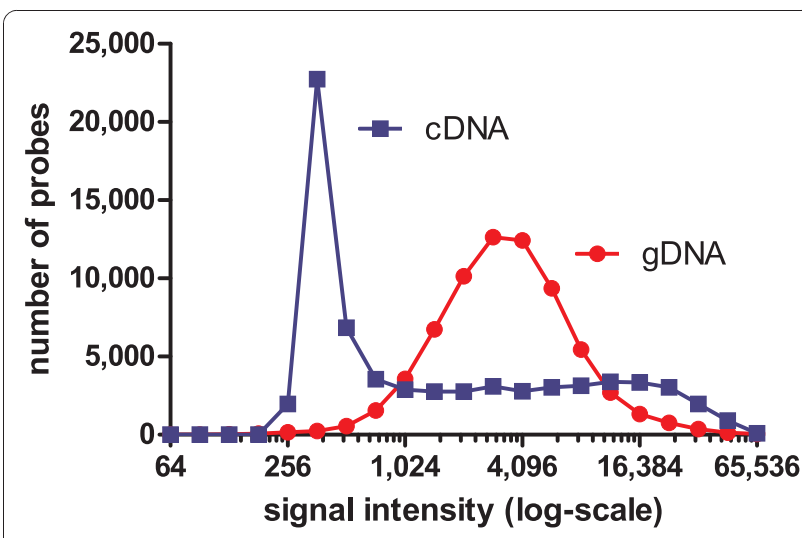

Figure 2 Comparison of microarray experiments performed by hybridization of gDNA and cDNA. The gDNA curve corresponds to the distribution of the Cy3-channel signals from the referencereference experiment, while the CDNA curve represents the first control sample of a previous gene expression experiment carried out with the same strain and the same array under similar hybridization conditions [15]. In cDNA experiments, many targets are present at low copy number (low signal) and a few sequences are present in high copy number (high signal). In contrast, in gDNA experiments, most targets are present at the same copy number, resulting in a peak at medium intensity. 
abundance, resulting in many probes giving low signals and overall lower signal to noise ratios. In the light of these findings, and as the nuclear genome within the same strain may be assumed to be constant, all CGH experiments were only carried out with a single replicate. Changes in the content of organellar DNA could theoretically also be detected using our experimental setup. However, this would require testing biological replicates as the number of organelles and/or their DNA content may be subject to variations according to the conditions of the culture [22-24]. These changes were therefore not examined in this study.

\section{Marked genetic differences support the presence of cryptic species}

CGH analysis of the different strains indicated that strains 1 and 2, which are known to be fully compatible $[9,21]$, have very similar genome sequences: the standard deviation of the $\log 2$-ratios from the array comparison for these strains was 0.3 (see Figure 3 for a distribution of $\log 2$-ratios), which was the same as that obtained for the reference-reference hybridization using two independent samples of strain 1 , and close to values obtained for similar experiments in bacteria [25].

In comparison, for the freshwater- and copper-tolerant strains (strains 3 and 4), standard deviations, compared to the reference strain, were 0.8 and 0.7 respectively. These values were close to the value obtained for the outgroup strain (E. fasciculatus, strain 5), which was 0.9. These data agree well the phylogenetic tree of the examined strains (Figure 1), supporting the idea that E. siliculosus may be a complex of several (cryptic) species [8-10].

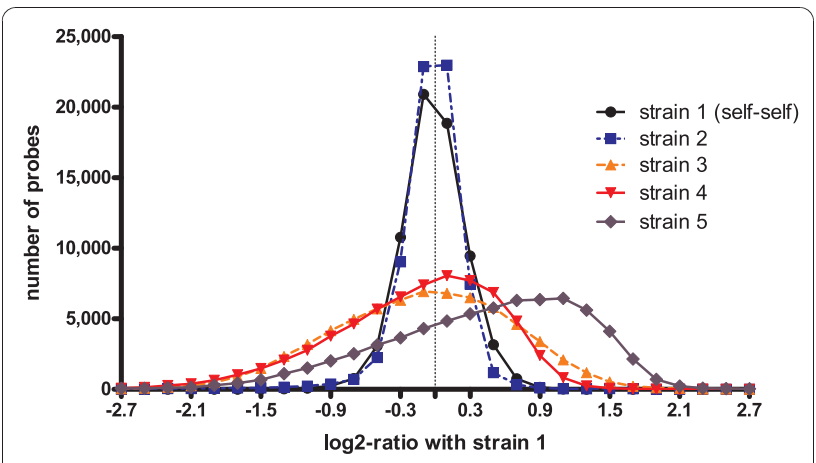

Figure 3 Distribution of log2-ratios (sample strain/reference strain 1) in the examined strains of Ectocarpus. "Strain 1" designates a reference-reference hybridization of two independent samples of strain 1. The apparent shift of the curve for strain 5 towards positive values is likely to be an artefact caused by the normalization procedure. Probe frequencies were calculated in intervals of 0.2 .

\section{Selection of conserved probes for future microarray experiments}

In spite of the marked genetic differences between strains, analysis of the DNA hybridization data showed that the microarray can still be exploited to analyze gene expression in all the strains tested except for strain 5 (see below), provided only conserved probes are selected for the analysis [19]. If a very stringent threshold for masking probes in cross strain experiments was chosen, e.g. 0.5 (1.4-fold change in signal intensity), a number of probes could be retained from microarray experiments: 64,608 (95\%), 32,501 (48\%), and 36,336 (53\%) for strains 2, 3, and 4, respectively. Moreover, because each sequence is represented by four probes, expression profiles may be obtained for 16,845 (98\%, strain 2), 14,554 (85\%, strain $3)$, and 15,078 ( $88 \%$, strain 4$)$ sequences, respectively. In many cases, i.e. in experiments that do not rely on direct inter-strain comparisons but rather on comparison of the same strain submitted to different treatments, a less stringent cut-off such as an absolute log2-ratio of 1 may be more appropriate, and would allow even more probes to be retained.

For strain 5, our current analysis does not provide any reliable selection criteria for conserved probes, as Figure 3 indicates that a bias might have been introduced during the normalization procedure. Unless specific probes are used for normalization, most normalization algorithms assume that the majority of probes yield similar signals for both of the examined samples. Although we used the popLowess algorithm [26], which has been designed to be less sensitive to copy number imbalances (or changes in sequence), we observed a high number of probes that exhibit a $\log 2$-ratio of 1.1 (Figure 3) for strain 5 . The maximum number of probes would be expected at a $\log 2$-ratio of 0 , as for the other strains, and a shift towards positive values suggests that the number of divergent probes was too high for the algorithm to function correctly. This strain was therefore excluded from further analyses.

To facilitate the selection of probes for strains 2 to 4 , we created a Java application, which can be used to remove a list of probes from raw pair files, prior to normalization using the NimbleScan software (Additional file 1). Along with this program, we also provide a list of all probes with $\log 2$-changes greater than 0.5 and greater than 1 . In addition, this program could also be applied to our data to pre-select probes based on their absolute signal intensity rather than the similarity between test- and reference strain. This approach has been suggested to decrease noise in RNA-based crossspecies hybridizations [20,27], but was not further explored here, as unlike in typical gene expression experiments, almost all probes produced medium to high intensity signals (Figure 2). 


\section{Putative deletions/duplications were detected mainly in} strain 2

To determine whether the divergent probes were distributed randomly throughout the genome, the normalized $\log 2$-ratios of strains 1-4 were analyzed at two levels: at the regional level, in order to determine highly variable genomic regions as well as duplications or deletions, and at the gene or EST level, to determine if particular functional groups of genes exhibited higher differences than others.

For the first (regional) analysis, microarray probes were positioned on the various genomic supercontigs and sets of 30 probes were screened using a sliding window approach (see Methods). Three areas with markedly different hybridization patterns were detected (Figure 4). Each region was then examined using quantitative PCR (Table 2). One of the three differences was found in strain 3, where a small region on Sctg_16 containing mainly transposable elements (TEs), had significantly lower signals compared to the reference strain (2-fold in the CGH experiment, 1.2-fold in the quantitative PCR validation), and will be discussed below. The two other regions were both found to differ between strains 1 and 2 , which are the genetically closest strains. One concerned the E. siliculosus virus 1 (EsV-1), and the second a rather small genomic Sctg, both of which will be discussed in the following section.

Differences with respect to a viral integration site and to a region of unknown function between strains 1 and 2 In strain 1, a large DNA virus closely related to EsV-1 [28] was identified in genomic Sctg_52. In spite of the presence of this virus in the genome, symptoms of viral infection have not been observed in this strain, and transcriptomic data suggested that the viral genes are not transcribed [7]. As strains 3 and 4 showed similar signal intensities in this region compared to the reference strain, both strains may also contain the viral genome, although, as with the reference strain, production of viral particles was not observed.

In strain 2, the region of the viral insertion on Sctg_52 exhibited 2.2-fold lower signal intensities compared to strain 1 (Figure 4). Nevertheless, for several genes of this Sctg, the $\log 2$-ratio between the two strains reached zero, and even positive values in one case (viral gene EsV-1-231, Figure 4). As the viral genome is present in a single copy in the reference strain, this difference could be due either to the absence of viral sequences within the genome of strain 2, in which case the remaining signals for strain 2 could be explained either by non-specific binding, or by the presence of highly divergent EsV-1-like sequences, such as a degenerated version of EsV-1. In cultures of strain 2, we have not observed any symptoms of viral infection.

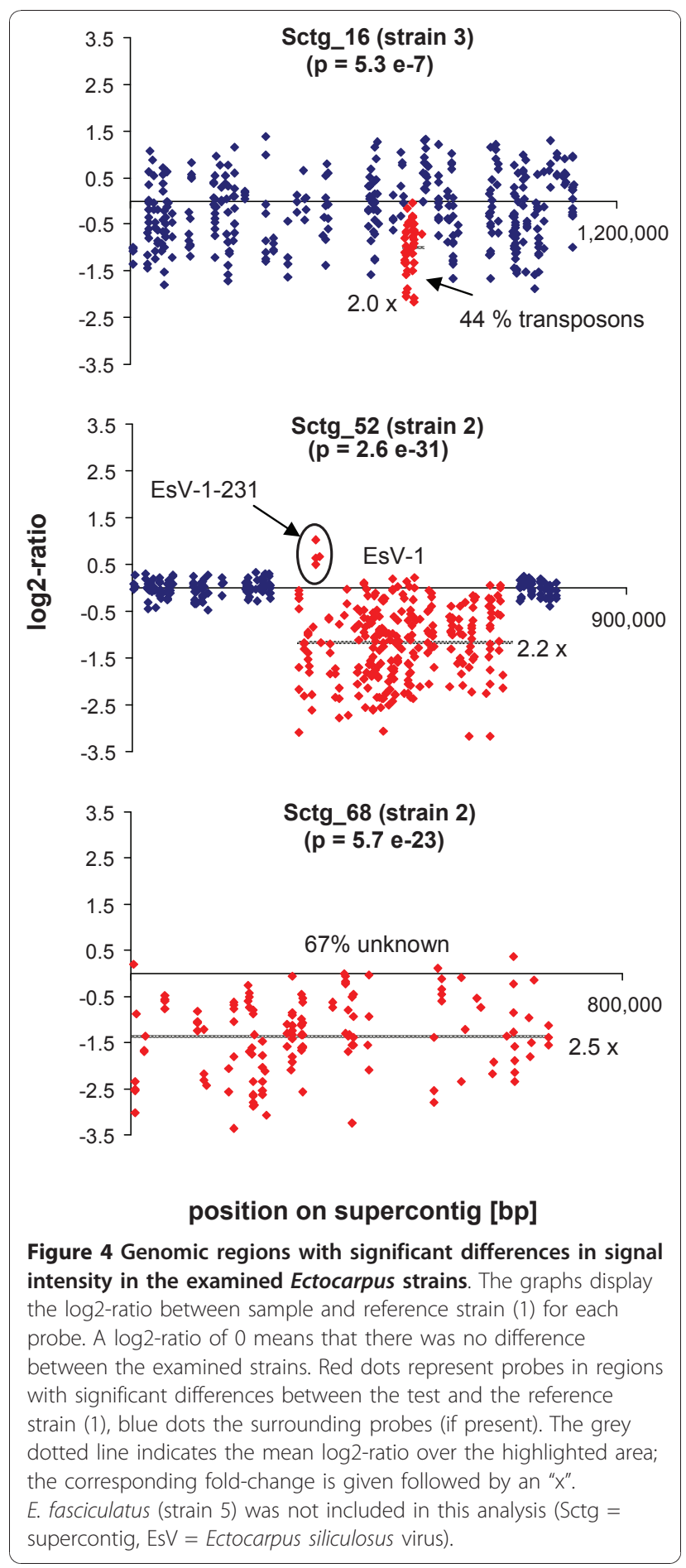

An alternative explanation can be provided by an observation made in a previous study: Müller et al. [29] detected amplification of a viral gene in a population of Ectocarpus sp. at different annealing temperatures depending on the individual, suggesting the presence of several distinct, but genetically similar, viruses within the same population. The hypothesis that strain 2 
Table 2 Quantitative PCR validation of the CGH experiments

\begin{tabular}{|c|c|c|c|c|c|c|c|}
\hline $\begin{array}{l}\text { Gene/ } \\
\text { region }\end{array}$ & forward primer & reverse primer & $\begin{array}{l}\text { amplification } \\
\text { efficiency (\%) }\end{array}$ & $\begin{array}{l}\text { reference } \\
\text { strain }\end{array}$ & $\begin{array}{l}\text { experi- } \\
\text { mental } \\
\text { strain }\end{array}$ & $\begin{array}{l}\text { ratio } \\
\text { (mean } \pm \\
S D, n= \\
3 \text { ) }\end{array}$ & $\begin{array}{l}\text { ratio for } \\
\text { region } \\
(\mathrm{CGH})\end{array}$ \\
\hline $\begin{array}{l}\text { R26S } \\
\text { (ref. } \\
\text { gene) }\end{array}$ & GCTAGGCTTGCGTTTGTGTG & GGCGAGACAGAAAGATTCCG & 108 & strain 1 & $\begin{array}{l}\text { strain } \\
2 / 3\end{array}$ & - & - \\
\hline $\begin{array}{l}\text { Dynein } \\
\text { (ref. } \\
\text { gene) }\end{array}$ & GGAACAAAGCATGGTGACAACA & CGCGTGCCTATCCAAGCT & 97 & strain 1 & $\begin{array}{l}\text { strain } \\
2 / 3\end{array}$ & - & - \\
\hline$\overline{\text { Sctg_16 }}$ & GCGTGCGTGCTTGGAAGG & TTCGGCTGCTGAGAGTGGAG & 96 & strain 1 & strain 3 & $0.9 \pm 0.04$ & 0.5 \\
\hline Sctg_16 & CAACCGCTCTCCACCATTCAG & GACGCCTTCACAGTATCACACC & 96 & strain 1 & strain 3 & $0.7 \pm 0.02$ & \\
\hline Sctg_16 & AACGATAGAGCGAGACGAGAGAG & GGAAGCAGATGGACACGAGTAAC & 93 & strain 1 & strain 3 & $0.8 \pm 0.03$ & \\
\hline Sctg_68 & CTCCTATCGCCCTGTGGTCTC & ACTGCCTCTATGGTCCGTCTTG & 100 & strain 1 & strain 2 & $1.0 \pm 0.1$ & 0.4 \\
\hline Sctg_68 & GTGAGAGAAACAACAGAGCAATACAG & ATGGAACCGCAGACAACAAGC & 102 & strain 1 & strain 2 & $0.6 \pm 0.2$ & \\
\hline Sctg_68 & TCCGACCTGACGAGCATTGG & CAGTGTGCGGTGCGAACG & 103 & strain 1 & strain 2 & $n / a^{*}$ & \\
\hline Sctg_68 & AAACACCTCCCAACCAACCAATC & AACGCAACGAGCAACCTTCC & 100 & strain 1 & strain 2 & $n / a^{*}$ & \\
\hline$\overline{E S V-1}$ & TAAGTTGATATTAGTGACAGTAGCAGGAG & GCCACGGAGGACGGAGATAC & 101 & strain 1 & strain 2 & $\mathrm{n} / \mathrm{a}^{*}$ & 0.5 \\
\hline EsV-1 & ACCACGATGCCTGTCTCCTTAC & TCCTCAGCCGCCAGAATACG & 95 & strain 1 & strain 2 & $\mathrm{n} / \mathrm{a}^{*}$ & \\
\hline EsV-1 & СTCCTCCGTAACCGTTGACATTG & CCGACCAGTAAACCCGTAAACC & 101 & strain 1 & strain 2 & $\mathrm{n} / \mathrm{a}^{*}$ & \\
\hline
\end{tabular}

* no amplification in experimental strain, or difference $>10$ cycles.

Primers and validation results for each tested genomic region (EsV-1 = region on Sctg_52 containing the E. siliculous virus 1 genes, ref. gene = reference gene). The amplification efficiency was calculated from the standard curve for strain 1.

contains such a related E. siliculosus virus integrated into its genome would agree with the profiles observed in this study. Further information about the viral genes potentially present in strain 2 , including their insertion sites, might provide clues as to which common features could be responsible for the silencing of viral gene expression.

The second region exhibiting significant differences between strain 1 and strain 2 was a small supercontig (Sctg_68). Just as for the EsV-1 region, signals were significantly lower in strain 2 (2.5-fold on average), and in the quantitative PCR analysis two of four primer pairs amplified only in strain 1, while two others indicated no or only a 1.7 -fold decrease (factor 0.6 , Table 2 ) in strain 2. Again, these differences could be due to two reasons: deletion(s), or very high variability of this region in strain 2 . The first hypothesis seems unlikely because of the wide range of differences in signal intensities on Sctg_68 ( $\log 2$-ratios from -3.4 to 0.4), comprising several probes with ratios close to 0 . Furthermore two of the four primer pairs also yielded amplicons in strain 2. Regarding the second hypothesis based on low sequence identity between the strains, sex related differences could provide a possible explanation and work is currently being carried out to test this hypothesis (Coelho \& Cock, personal communication). Sctg_68 is predicted to encode 21 proteins, 14 of which are (conserved) hypothetical proteins with unknown functions.

\section{Functional analysis of highly conserved and highly variable genes}

To identify functional groups of genes that were subject to particularly high conservation or variation, we examined each of the contigs and singletons used for the design of the array. Contigs and singletons were defined as "conserved" if none of the four probes associated with each sequence exhibited an absolute log2-ratio with the reference strain $>1$, and as "variable" if two or more probes exhibited an absolute $\log 2$-ratio with the reference strain $>1$. We then searched for enrichment of GO terms among the sequences classified as variable for strains 2-4, as well as among the sequences classified as "conserved" in all of these strains.

One of the problems with this sort of analysis is that probes located within the untranslated region (UTR) are usually less conserved than probes located in the coding sequence (CDS). In our dataset the overall proportion of probes located within the UTR of a gene was $62 \%$ $(42,073 / 68,270)$. However, when considering only the most variable probes (absolute $\log 2$-ratio $>1$ ) this percentage increased to $67 \%(688 / 1,012), 73 \%(9,585 /$ $13,141)$ and $84 \%(8,764 / 10,369)$ in strains 2,3 , and 4 respectively. This phenomenon will be termed UTR bias hereafter, and could potentially lead to the identification of functional groups of genes as highly variable or highly conserved, based on the percentage of probes that have been designed in the UTRs for this group. Therefore, in the following section, we assess the percentage of CDS or 
UTR probes for each functional group identified, and perform comparisons using both the entire data set as well as only the UTR probes as reference where necessary.

\section{A set of 7,497 sequences were conserved in all the E. siliculosus strains analyzed}

In accordance with our estimation of the overall genetic differences between the examined strains, we found that in strain $297 \%$ of all sequences were considered conserved with respect to strain 1 (absolute $\log 2$-ratio $<1$ for all four probes), while in strains 3 and 4 this was only the case for $53 \%$ and $63 \%$ of the sequences, respectively (Figure 5). These findings are in agreement with the ITS tree and the corresponding genetic distances reported in Figure 1. Furthermore, we identified a set of 7,479 (44\%) core sequences, which were considered conserved in all four examined strains of E. siliculosus. An automatic analysis of these sequences highlighted only one GO (Gene Ontology) category (FDR < 0.05): "Structural constituent of ribosomes". In contrast to this, a similar study conducted between two soybean species [20] identified

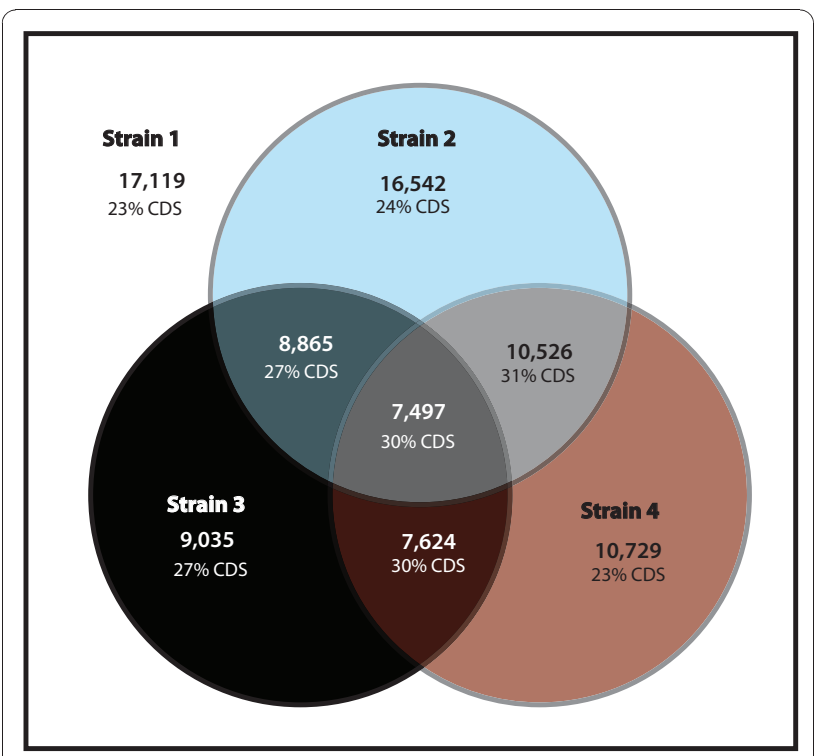

Figure $\mathbf{5}$ Venn diagram indicating the number of conserved sequences in tested strains of $\boldsymbol{E}$. siliculosus. A sequence was considered to be conserved when all four probes corresponding to this sequence exhibited an absolute log2-ratio with the control $<1$. The first number indicates the total count of ESTs derived sequences (singletons and contigs) conserved between the strains, and the percentage of these sequences represented only by probes in the CDS region is given below. The number in the center of the graph, for example, indicates that 7,497 sequences are conserved between strain 1, 2, 3, and 4, while the number in the blue circle above shows that 16,542 sequences were conserved between strain 1 and strain 2. Please note that strain 1 is the basis of all comparisons, as only genes that are present in this strain are represented on the array. Strain 5 was not included in this analysis due to the bias introduced by the normalization procedure. numerous GO terms, including some related to photosynthesis and transporters. The differences between these two studies may, however, be related to the respective methodological approaches. While Yang et al. [20] examined absolute signals derived from hybridization of cRNA, we examined the relative change in signal from gDNA hybridization and thus eliminated any possible bias introduced by differences in gene expression levels. An assessment of the effects of the UTR bias on the results obtained for sequences annotated as structural constituents of the ribosome in our study revealed that only 18 (i.e. $11 \%$, vs. $23 \%$ in the entire dataset) contained only CDS probes (i.e. sequences for which all four probes are located in the CDS), and the overall percentage of CDS probes in these sequences was $40 \%$ (vs. $38 \%$ in the entire dataset). UTR bias was therefore not an issue for these sequences.

\section{Transposable elements and fucoxanthin-chlorophyll a/c} binding proteins are among the most variable sequences Strain 2 was compared with the reference strain 1 to identify sequences that exhibited a high degree of variability between the two strains. We found only 264 sequences that contained at least two probes with an absolute $\log 2$-ratio > 1 , and an automatic search for enriched GO categories in this subset did not yield any significant results, but we identified 18 TEs $(6.8 \%$ of the sequences mentioned above) that were part of the database of known Ectocarpus TEs [7]. In comparison, the entire dataset contains 284 known transposons (i.e. TEs represent $1.7 \%$ of the entire dataset).

For strains 3 and 4, we identified 3,343 and 2,563 sequences respectively that matched our selection criteria (i.e. at least two probes with an absolute log2-ratio of the test strain to reference strain $>1$ ). An automated search for enriched GO terms $(F D R<0.05)$ in this set of sequences yielded only one GO-category, i.e. chlorophyll binding, which consists mainly of fucoxanthinchlorophyll a/c binding proteins (FCPs). We then completed the list of FCPs using a list of sequences identified by manual annotation [7] (Additional file 2). Highly variable probes were found to be significantly overrepresented also among the complete set of 144. FCP probes on the array. Although FCPs were represented by a higher proportion of UTR probes $(112 / 144,78 \%)$ compared to the entire dataset (62\%), the over-representation of highly variable probes among FCPs was also statistically significant when comparing the FCP probes to only the UTR probes as background (Figure 6A). This confirms that UTR bias was not the primary reason for these genes being among the most variable.

In order to determine if high variability between strains was a feature common to other multigenic families, which merely remained undetected due to the lack of 


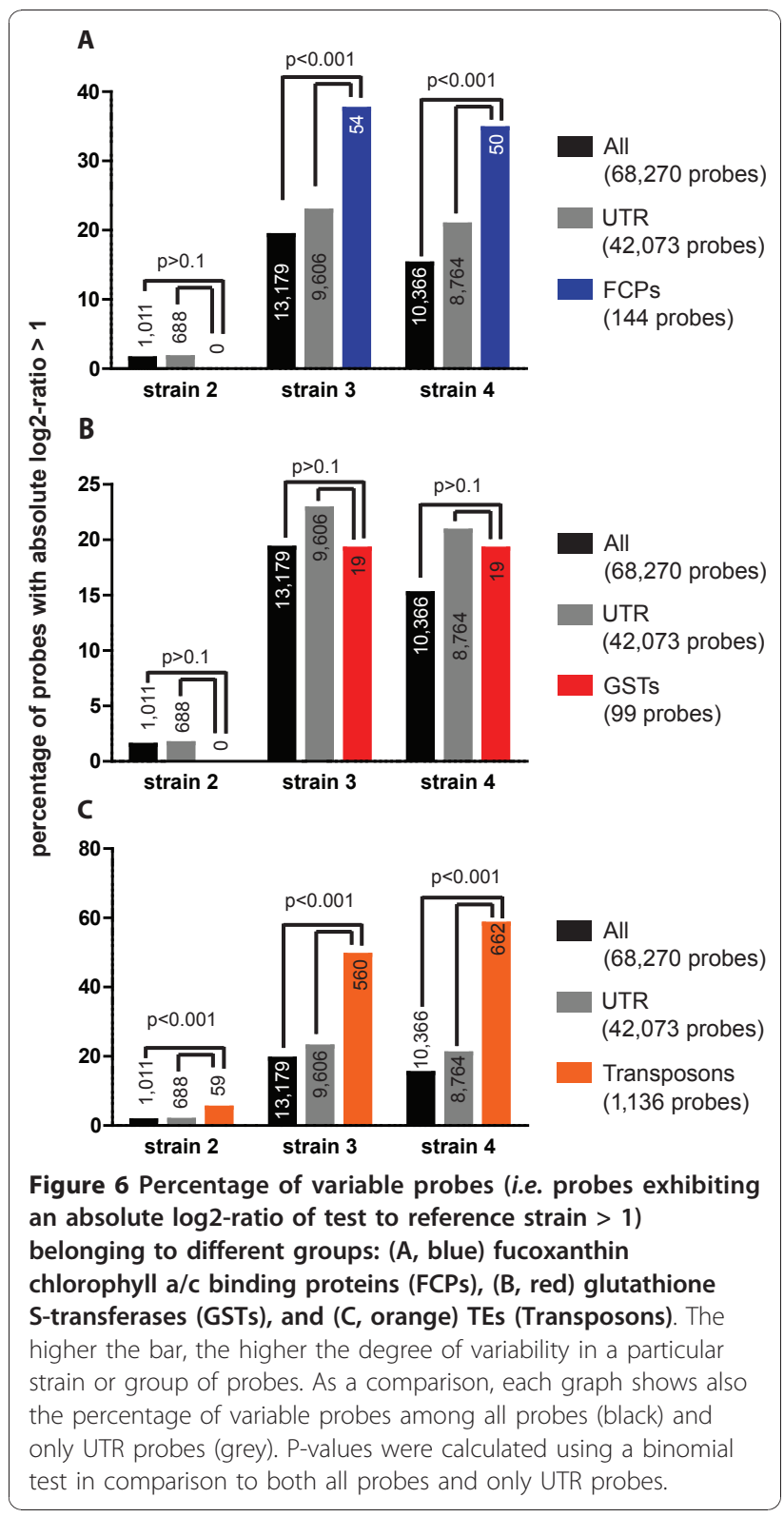

high quality automatic annotations for some of them, we performed the same analysis for probes corresponding to 25 manually annotated glutathione-S-transferases (GSTs; Additional file 2, [30]). Our analysis did not reveal any significant differences between GSTs and the rest of the genes ( $p>0.1$ Figure 6B). This shows that not all multigenic families are subject to high variability in different strains of Ectocarpus.

Finally, as automatic GO annotations did not include annotations for TEs, but since they were highly represented among the sequences found most variable in strain 2 (see above), they were analyzed separately. The 1,136 probes corresponding to the 284 transposons represented on the array (see Additional file 2 and
Methods) were significantly overrepresented among the highly variable probes in all E. siliculosus strains (Figure 6C), both when the entire dataset or only the UTR probes were used as a basis for the comparison.

There may be several reasons why certain sequences are less conserved than others. Certain genes or genomic regions may be at increased risk of targeted deletions via recombination events [31,32]. Others might be essential for the adaptation to different environments, and thus subject to different selective pressures as demonstrated for rapidly evolving proteins in two species of Arabidopsis [33]. Although we can presently only speculate about the importance of FCPs and transposons for this latter process, both categories of sequences have been recently discussed in this context for heterokonts and other organisms.

FCPs are part of the light harvesting complex, and are thought to function primarily in the transmission of light energy to chlorophyll. Recent transcriptomic studies in Chaetoceros and in Ectocarpus, however, showed some FCPs to be transcriptionally induced in response to stress $[15,34]$. Other FCPs have also been shown to be differentially expressed in the gametophyte and sporophyte generations of Ectocarpus [35]. In the green alga Chlamydomonas reinhardtii [36] and in the diatom Cyclotella meneghiniana [37,38], FCP-related proteins have also been recently implicated in the process of non-photochemical quenching. The Ectocarpus genome contains a total of 53 FCPs, a multitude that may be related to the adaptation to highly variable light conditions in the intertidal and shallow subtidal zones $[7,39]$. Many of the E. siliculosus FCPs share a high degree of sequence similarity, and some are located in close proximity on the same supercontig, both observations suggesting recent gene duplications within this family. The recent expansion of the FCP family in E. siliculosus, as well as the evidence for high variations between different strains of Ectocarpus presented in this study, would agree with the hypothesis that FCPs have evolved or are evolving to serve different functions within the chloroplast, and with their potential role in the adaptation to different environments $[7,39,40]$.

TEs are a major component of many eukaryotic genomes, and often considered as "junk" DNA or genomic parasites [41]. However, there may be a limited number of instances where they could confer benefits. For example, certain transposons have recently been suggested to play a role in the adaptation of Drosophila to temperate environments [42,43]. A study in diatoms (which are also members of the heterokont lineage) proposed that retrotransposons may promote genome rearrangements, thus possibly conferring phenotypic plasticity to an individual species, and aiding the adaptation to different environments [44]. Two important ways of controlling 
transposons are silencing by methylation and RNAi-like mechanisms [41]. Our findings that TEs were among the most variable components of the Ectocarpus genome, and that even very closely related strains (strains 1 and 2) differed with respect to these sequences, are in agreement with the observation that TEs in Ectocarpus are both highly expressed and are not methylated [7].

Neither in the case of transposons nor in the case of FCPs does our study present any proof of a direct relationship to the adaptation to different or extreme environments. It does, however, highlight both groups as promising subjects for future studies examining this question.

\section{Conclusion}

This study is the first microarray based genomic comparison of different brown algal strains. It enabled the detection of significant genomic variations between different ecotypes thought to belong to the same species, supporting the hypothesis of several cryptic species within E. siliculosus. At the same time, it provided a set of conserved probes which can be used for future transcriptomic experiments using the microarray available for the genome-sequenced strain and analyzing three of the four examined test strains.

In addition, further analysis of the CGH results provided first indications of differences with respect to an EsV-1 insertion in the genome of one of the examined strains, highlighting a potentially interesting candidate for the study of viral diversity as well as differences in integration sites. Finally, an analysis of the most variable microarray probes demonstrated that several functional elements of the Ectocarpus genome were likely to evolve at different rates. Both TEs and FCPs were identified as part of the most variable elements in terms of copy number and/or sequence identity, and could be of importance in the evolution of different strains of Ectocarpus. Together these results pave the way for further studies to explore the biology and the adaptation of the examined ecotypes to their respective environments.

\section{Methods}

Algal strains and culture conditions

All strains were clonal isolates and cultivated in 10-liter plastic flasks in a culture room at $13-14^{\circ} \mathrm{C}$ using filtered and autoclaved natural seawater enriched according to Provasoli [45]. Although none of the examined strains were axenic, cultures were handled under axenic conditions, and bacterial contamination could not be detected using light microscopy. Cultures were irradiated by daylight-type fluorescent white light $\left(40 \mu \mathrm{Em}^{-2} \mathrm{~s}^{-1}\right)$ under a $14 / 10$ light-dark cycle and were permanently aerated with filtered $(0.22 \mu \mathrm{m})$ compressed air.
DNA extraction and fragmentation, and ITS1 sequencing Approximately $1 \mathrm{~g}$ (wet weight) of algal material was harvested by filtration, dried with a paper towel, and frozen in liquid nitrogen. These samples were used for DNA extraction using CsCl-gradient purification based on the protocol described by Apt et al. [46] with modifications as described by Le Bail et al. [47]. The ITS1 sequence of strain 3 was determined as described by Peters et al. [9], and sequences of the other strains were available from public databases. Accession numbers are provided in Table 1. For the calculation of the tree displayed in Figure 1, the BIONJ algorithm [48] was used with default parameters and bootstrapping (100 replicates). ITS sequences of strain 1-5 were aligned using MAFFT [49] and the L-INS-i strategy, and conserved bases were selected using the Gblocks server [50], allowing smaller final blocks and less strict flanking positions.

\section{Hybridization and scanning}

The genomes of the five selected strains were analyzed by hybridizing fluorescently labeled gDNA of the five strains to an EST-based Roche NimbleGen 4-plex expression array [ArrayExpress: A-MEXP-1445]. This array represents 8,165 contigs and 8,874 singletons by four unique 60 -mer probes each. [15]. The array furthermore contained probes for 231 sequences of EsV-1 [28]. A closely related virus is present as an integrated sequence in the genome of the Ectocarpus genome strain 1 [7]. Note that, in some cases, a gene may be represented by more than one cDNA contig/ singleton. In total, the array covers about 10,600 (i.e. $65 \%$ ) of the 16,256 predicted unique genes in the genome. Strain 1 represented the reference strain. For each sample, one $\mu \mathrm{g}$ of fragmented DNA was labeled using the Roche NimbleGen Dual-Color DNA Labeling Kit (Roche NimbleGen, Madison, WI, USA) following the manufacturer-supplied CGH Analysis protocol v5.1. Reference DNA (strain 1) was labeled with Cy5 and test DNAs (strain 2-5) with Cy3. In addition, a reference-reference hybridization was carried out using two independent DNA samples from strain 1, one labeled with $\mathrm{Cy} 3$ and the other with Cy5. One $\mu \mathrm{g}$ of DNA was used for each labeling reaction which yielded $>4 \mu \mathrm{g}$ of labeled DNA. Four $\mu \mathrm{g}$ of each sample were hybridized together with $4 \mu \mathrm{g}$ of the reference DNA (strain 1), using the Roche NimbleGen Hybridization System 4 and following the standard Roche NimbleGen protocol (CGH Analysis protocol v5.1). Scanning was performed according to the same protocol using a Genepix 4200AL scanner and the Genepix pro 5.0 software (Molecular Devices, Sunnyvale, CA, USA). 


\section{Normalization}

Scanned images were imported into NimbleScan version 2.4 (Roche NimbleGen, Madison, WI, USA), and the raw signal intensity was extracted for each probe according to the Roche NimbleGen CGH Analysis user guide (available in the protocols section of our Array Express submission; see below). This protocol does not include a background subtraction step, which might lead to a slight underestimation of $\log 2$-ratios for probes with low signals. A “.pos" file (Additional file 3) for our microarray was generated by blasting each of the microarray probes against the entire Ectocarpus genome (EMBL accession numbers CABU01000001-CABU01013533, FN647682FN649242, FN649726-FN649760, [7]) using the megablast algorithm [51]. Each genomic supercontig was treated as a chromosome; 2,676 probes (3.9\%) could not be clearly assigned a position on the genome (homologous sequences were not found). These probes may correspond to low-quality sequences or contaminations and were assigned randomly to a "virtual" chromosome, which was later used to choose ideal parameters for the DNA copy number analysis (see below), but not considered for other analyses. Raw $\log 2$-ratios were normalized using the popLowess-algorithm version 1.0.2 [26] and R http://www.r-project.org version 2.9.1/Bioconductor version $2.3 \mathrm{http}$ ://www.bioconductor.org. The popLowess algorithm selects a subset (a population) of probes with very similar signals and uses this subset to normalize the entire dataset, thus making the algorithm less sensitive to copy number imbalances (or changes in sequence). The following parameters were used: significance threshold for accepting change points $=0.05$, smoother $\operatorname{span}=1 / 3$, 4 iterations, and $\delta=0.1$.

\section{Statistical and functional analysis}

Normalized $\log 2$-ratios of strains 1-4 were analyzed at two levels: at the regional level by examining sets of 30 probes using a sliding window approach, and at the gene or EST (singletons and contigs) level. For the analysis at the regional level, normalized expression values were imported into the Partek Genome Suite software version 6 (Partek Inc., St. Louis, MO, USA), which was used for scanning for copy number alterations using circular binary segmentation (CBS, [52]). This method detects regions with potential duplications and deletions in the genome, and assigns them a p-value. Please note that these p-values, unlike those from the qPCR validation, are merely based on the signal intensities of different probes within one biological replicate. For our analysis, only segments with at least 30 probes and a mean $\log 2$-ratio greater than 1 or less than -1 were considered, because these settings yielded no false positives on the "virtual" chromosome, while still allowing to detect relatively short deletions or duplications with a minimum length of 7 to 8 genes. We chose to apply a p-value cutoff of $7.4 \mathrm{e}-7$, which corresponds to a p-value of 0.05 after a Bonferroni correction for 68,240 tests (i.e. the maximum number of possible windows of 30 probes). Since the tested windows overlapped, the latter assumption is very conservative. However, less stringent methods would not have changed the number or identity of the identified genomic regions as the p-value of the next most significant segment was three orders of magnitude above our cutoff.

Data were also analyzed at the EST level (singletons and contigs represented on the array). We selected all sequences with at least 2 of the 4 probes showing an absolute $\log 2$-ratio between test strain and reference strain $>1$, for each of the four strains, as well as sequences conserved in all strains (i.e. all four probes exhibited absolute log2-ratios with the reference strain $<1)$. Using the GO annotations generated in our previous study [15], enriched GO terms were searched for using the GOLEM software [53] and allowing a false discovery rate (FDR) of $5 \%$. The proportion of variable probes (absolute log2-ratio > 1) in the identified groups was compared to that in all probes (UTR + CDS) as well as to that in only the UTR probes by means of a binomial test. TEs were identified by sequence homology with a database of known E. siliculosus transposons [7]. Only sequences with $>80 \%$ sequence similarity over at least $400 \mathrm{bp}$ were considered.

\section{Validation}

Genomic regions that yielded significantly different signals between the reference and test strains were verified by real time quantitative PCR on genomic DNA of three biological replicates, as described previously [47]. Three to four fragments were amplified and quantified per region using $4 \mathrm{ng}$ of gDNA as template and the primer pairs listed in Table 2. Standard curves were created to calculate the reaction efficiency for each primer pair using a dilution series of 16, 8, 4, 2, 1 and $0 \mathrm{ng}$ of gDNA. The specificity of the amplification as well as possible size differences in the amplicon were checked using a melting curve. Dynein (Esi0298_0008 = LQ0AAB30YA12FM1) and R26S (Esi0072_0068 = CL461Contig1) were selected as reference genes because of their high degree of conservation in our study (log2-ratio < 0.2 in all E. siliculosus strains).

\section{Data deposition}

CGH-data (raw and normalized) for strains 2 to 5 were deposited in the ArrayExpress database under accession number ArrayExpress: E-TABM-766. The referencereference hybridization is available under accession ArrayExpress: E-TABM-967. 


\section{Additional material}

Additional file 1: List of probes with absolute log2-ratios $>0.5$ and $>1$ for all examined strains of $E$. siliculosus.

Additional file 2: List of EST derived sequences (singletons and contigs) used for the analysis of FCPs, GSTs, TEs, as well as the corresponding gene models in the Ectocarpus genome (for FCPs and GSTs).

Additional file 3: ".pos" file generated for the $E$. siliculosus gene expression array version 1

\section{Abbreviations}

CDS: coding sequence; CGH: comparative genome hybridization; EST: expressed sequence tag; EsV-1: Ectocarpus siliculosus virus 1; FCP: fucoxanthin a/c chlorophyll binding protein; FDR: false discovery rate; gDNA: genomic DNA; GO: gene ontology; GST: glutathione S-transferase; ITS1: internal transcribed spacer 1; TE: transposable element; UTR: untranslated region.

\section{Acknowledgements}

We would like to thank Declan Schroeder for helpful discussions, Aude Le Bail for providing material of strain 2, and Andrés Ritter for providing material of strain 4. SD received funding from the European community's Sixth Framework Programme (contract n MESTCT 2005-020737).

\section{Author details}

${ }^{1}$ UPMC Univ Paris 6, UMR 7139 Marine Plants and Biomolecules, Station Biologique, 29680 Roscoff, France. ${ }^{2}$ CNRS, UMR 7139 Marine Plants and Biomolecules, Station Biologique, 29680 Roscoff, France. ${ }^{3}$ Current Address: Department of Biology, University of Oslo, P.O. Box 1066 Blindern, N-0316 Oslo, Norway. ${ }^{4}$ Institut Pasteur, Plate-Forme 2- Puces à ADN, 25 rue du docteur Roux, 75724 Paris Cedex 15, France. ${ }^{5}$ BEZHIN ROSKO, 40 rue des pêcheurs, 29250 Santec, France. ${ }^{6}$ MBA Laboratory, Citadel Hill, Plymouth PL1 2PB, UK.

\section{Authors' contributions}

$\Pi$ and SMD conceived the study, together with CB and JYC. CP, SMD, TT, and SR performed the lab-work, and SMD and CP analyzed the results. SMD drafted the manuscript together with $\Pi$, JMC, CB, and AFP. All authors approved the final manuscript.

Received: 4 August 2010 Accepted: 13 January 2011 Published: 13 January 2011

\section{References}

1. Zemke-White WL, Ohno M: World seaweed utilisation: an end-of-century summary. J Appl Phycol 11:369-376.

2. Bartsch I, Wiencke C, Bischof K, Buchholz CM, Buck BH, Eggert A, Feuerpfeil P, Hanelt D, Jacobsen S, Karez R, et al: The genus Laminaria sensu lato: recent insights and developments. Eur J Phycol 2008, 43:1-86.

3. Baldauf SL: An overview of the phylogeny and diversity of eukaryotes. $J$ Systemat Evol 2008, 46:263-273.

4. Coelho SM, Peters AF, Charrier B, Roze D, Destombe C, Valero M, Cock JM: Complex life cycles of multicellular eukaryotes: new approaches based on the use of model organisms. Gene 2007, 406:152-170.

5. Charrier B, Coelho SM, Le Bail A, Tonon T, Michel G, Potin P, Kloareg B, Boyen C, Peters AF, Cock JM: Development and physiology of the brown alga Ectocarpus siliculosus: two centuries of research. New Phytol 2008, 177:319-332.

6. Peters AF, Marie D, Scornet D, Kloareg B, Cock JM: Proposal of Ectocarpus siliculosus (Ectocarpales, Phaeophyceae) as a model organism for brown algal genetics and genomics. J Phycol 2004, 40:1079-1088.

7. Cock JM, Sterck L, Rouzé P, Scornet D, Allen AE, Amoutzias G, Anthouard V, Artiguenave F, Aury JM, Badger JH, et al: The Ectocarpus genome and the independent evolution of multicellularity in brown algae. Nature 2010, 465:617-621.

8. Stache-Crain B, Müller DG, Goff LJ: Molecular systematics of Ectocarpus and Kuckuckia (Ectocarpales, Phaeophyceae) inferred from phylogenetic analysis of nuclear- and plastid-encoded DNA sequences. J Phycol 1997 33:152-168.

9. Peters AF, Mann AD, Córdova CA, Brodie J, Correa JA, Schroeder DC Cock MJ: Genetic diversity of Ectocarpus (Ectocarpales, Phaeophyceae) in Peru and northern Chile, the area of origin of the genome-sequenced strain. New Phytol 2010, 188:30-41.

10. Peters AF, Van Wijk SJ, Cho GY, Scornet D, Hanyuda T, Kawai H, Schroeder DC, Cock MJ, Boo SM: Reinstatement of Ectocarpus crouaniorum Thuret in Le Jolis as a third common species of Ectocarpus (Ectocarpales, Phaeophyceae) in Western Europe, and its phenology at Roscoff, Brittany. Phycol Res 2010, 58:157-170.

11. McCauley LA, Wehr JD: Taxonomic reappraisal of the freshwater brown algae Bodanella, Ectocarpus, Heribaudiella, and Pleurocladia (Phaeophyceae) on the basis of $\mathrm{rbcL}$ sequences and morphological characters. Phycologia 2007, 46:429-439.

12. West J, Kraft G: Ectocarpus siliculosus (Dillwyn) Lyngb. from Hopkins River Falls, Victoria - the first record of a freshwater brown alga in Australia. Muelleria 1996, 9:29-33.

13. Ritter A, Ubertini M, Romac S, Gaillard F, Delage L, Mann A, Cock JM, Tonon T, Correa JA, Potin P: Copper stress proteomics highlights local adaptation of two strains of the model brown alga Ectocarpus siliculosus. Proteomics 2010, 10:2074-88.

14. Amtmann A: Learning from Evolution: Thellungiella generates new knowledge on essential and critical components of abiotic stress tolerance in plants. Mol Plant 2009, 2:3-12.

15. Dittami SM, Scornet D, Petit J, Corre E, Dondrup M, Glatting K, Sterck L, Peer $\mathrm{V}$, Cock JM, Boyen C, Tonon T: Global expression analysis of the brown alga Ectocarpus siliculosus (Phaeophyceae) reveals large-scale reprogramming of the transcriptome in response to abiotic stress. Genome Biol 2009, 10:R66.

16. Bar-Or C, Czosnek H, Koltai H: Cross-species microarray hybridizations: a developing tool for studying species diversity. Trends in Gen 2007, 23:200-207.

17. Ranz JM, Castillo-Davis Cl, Meiklejohn CD, Hartl DL: Sex-Dependent Gene Expression and Evolution of the Drosophila Transcriptome. Science 2003, 300:1742-1745

18. Hammond JP, Bowen HC, White PJ, Mills V, Pyke KA, Baker AJ, Whiting SN, May ST, Broadley MR: A comparison of the Thlaspi caerulescens and Thlaspi arvense shoot transcriptomes. New Phytol 2006, 170:239-60.

19. Hammond J, Broadley MR, Craigon D, Higgins J, Emmerson Z, Townsend H, White P, May S: Using genomic DNA-based probe-selection to improve the sensitivity of high-density oligonucleotide arrays when applied to heterologous species. Plant Methods 2005, 1:10.

20. Yang SS, Valdes-Lopez O, Xu WW, Bucciarelli B, Gronwald JW, Hernández G, Vance CP: Transcript profiling of common bean (Phaseolus vulgaris L.) using the GeneChip(R) Soybean Genome Array: optimizing analysis by masking biased probes. BMC Plant Biol 2010, 10:85.

21. Heesch S, Cho GY, Peters AF, Le Corguillé G, Falentin C, Boutet G, Coëdel S, Jubin C, Samson G, Corre E, et al: A sequence-tagged genetic map for the brown alga Ectocarpus siliculosus provides large-scale assembly of the genome sequence. New Phytol 2010, 188:42-51.

22. Lamppa GK, Bendich AJ: Changes in chloroplast DNA levels during development of pea (Pisum sativum). Plant Physiol 1979, 64:126-130.

23. Miyamura S, Nagata T, Kuroiwa T: Quantitative fluorescence microscopy on dynamic changes of plastid nucleoids during wheat development. Protoplasma 1986, 133:66-72.

24. Hiramatsu T, Misumi O, Kuroiwa T, Nakamura S: Morphological changes in mitochondrial and chloroplast nucleoids and mitochondria during the Chlamydomonas reinhardtii (Chlorophyceae) cell cycle. J Phycol 2006, 42:1048-1058.

25. Taboada EN, Acedillo RR, Luebbert CC, Findlay WA, Nash JH: A new approach for the analysis of bacterial microarray-based comparative genomic hybridization: insights from an empirical study. BMC Genomics 2005, 6:78.

26. Staaf J, Jönsson G, Ringnér M, Vallon-Christersson J: Normalization of arrayCGH data: influence of copy number imbalances. BMC Genomics 2007 , 8:382.

27. Ji W, Zhou W, Gregg K, Yu N, Davis S, Davis S: A method for cross-species gene expression analysis with high-density oligonucleotide arrays. Nucleic Acids Res 2004, 32:e93. 
28. Delaroque N, Müller DG, Bothe G, Pohl T, Knippers R, Boland W: The complete DNA sequence of the Ectocarpus siliculosus virus EsV-1 genome. Virology 2001, 287:112-132.

29. Müller DG, Westermeier R, Morales J, Reina G, Del Campo E, Correa JA, Rometsch E: Massive prevalence of viral DNA in Ectocarpus (Phaeophyceae, Ectocarpales) from two habitats in the North Atlantic and South Pacific. Bot Mar 2000, 43:157-159.

30. de Franco P, Rousvoal S, Tonon T, Boyen C: Whole genome survey of the glutathione transferase family in the brown algal model Ectocarpus siliculosus. Mar Genomics 2009, 1:135-148.

31. Buard J, Vergnaud G: Complex recombination events at the hypermutable minisatellite CEB1 (D2S90). EMBO J 1994, 13:3203-10.

32. Mézard C: Meiotic recombination hotspots in plants. Biochem Soc Transactions 2006, 34:531-4.

33. Barrier M, Bustamante CD, Yu J, Purugganan MD: Selection on rapidly evolving proteins in the Arabidopsis genome. Genetics 2003, 163:723-33.

34. Hwang YS, Jung $G$, Jin E: Transcriptome analysis of acclimatory responses to thermal stress in Antarctic algae. Biochem Biophys Res Com 2008, 367:635-641.

35. Peters AF, Scornet D, Ratin M, Charrier B, Monnier A, Merrien Y, Corre E, Coelho S, Cock JM: Life-cycle-generation-specific developmental processes are modified in the immediate upright mutant of the brown alga Ectocarpus siliculosus. Development 2008, 135:1503-1512.

36. Peers G, Truong TB, Ostendorf E, Busch A, Elrad D, Grossman AR, Hippler M, Niyogi KK: An ancient light-harvesting protein is critical for the regulation of algal photosynthesis. Nature 2009, 462:518-21.

37. Gundermann K, Büchel C: The fluorescence yield of the trimeric fucoxanthin-chlorophyll-protein FCPa in the diatom Cyclotella meneghiniana is dependent on the amount of bound diatoxanthin. Photosynthesis Res 2008, 95:229-35.

38. Beer A, Gundermann K, Beckmann J, Büchel C: Subunit composition and pigmentation of fucoxanthin-chlorophyll proteins in diatoms: evidence for a subunit involved in diadinoxanthin and diatoxanthin binding. Biochem 2006, 45:13046-53.

39. Dittami SM, Michel G, Collén J, Boyen C, Tonon T: Chlorophyll-binding proteins revisited - a multigenic family of light-harvesting and stress proteins from a brown algal perspective. BMC Evol Biol 2010, 10:365.

40. Neilson JA, Durnford DG: Structural and functional diversification of the light-harvesting complexes in photosynthetic eukaryotes. Photosynthesis Res 2010, 106:57-71.

41. Gogvadze E, Buzdin A: Retroelements and their impact on genome evolution and functioning. Cell Mol Life Sci 2009, 66:3727-3742.

42. González J, Karasov TL, Messer PW, Petrov DA: Genome-wide patterns of adaptation to temperate environments associated with transposable elements in Drosophila. PLoS Genetics 2010, 6:e1000905.

43. González J, Lenkov K, Lipatov M, Macpherson JM, Petrov DA: High rate of recent transposable element-induced adaptation in Drosophila melanogaster. PLoS Biology 2008, 6:e251.

44. Maumus F, Allen AE, Mhiri $C$, Hu H, Jabbari K, Vardi A, Grandbastien M, Bowler C: Potential impact of stress activated retrotransposons on genome evolution in a marine diatom. BMC Genomics 2009, 10:624.

45. Starr RC, Zeikus JA: Utex - the Culture Collection of Algae at the University of Texas at Austin 1993 List of Cultures. J Phycol 1993, 29:1-106.

46. Apt KE, Clendennen SK, Powers DA, Grossman AR: The gene family encoding the fucoxanthin chlorophyll proteins from the brown alga Macrocystis pyrifera. Mol Gen Genetics 1995, 246:455-464.

47. Le Bail A, Dittami SM, de Franco PO, Rousvoal S, Cock JM, Tonon T, Charrier B: Normalisation genes for expression analyses in the brown alga model Ectocarpus siliculosus. BMC Mol Biol 2008, 9:75.

48. Gascuel O: BIONJ: an improved version of the $\mathrm{NJ}$ algorithm based on a simple model of sequence data. Mol Biol Evol 1997, 14:685-695.

49. Katoh K, Misawa K, K-ichi Kuma, Miyata T: MAFFT: a novel method for rapid multiple sequence alignment based on fast Fourier transform. Nucleic Acids Res 2002, 30:3059-66.

50. Talavera G, Castresana J: Improvement of phylogenies after removing divergent and ambiguously aligned blocks from protein sequence alignments. Systematic Biol 2007, 56:564-77.

51. Zhang Z, Schwartz S, Wagner L, Miller W: A greedy algorithm for aligning DNA sequences. J Comp Biol 2000, 7:203-14.
52. Olshen $A B$, Venkatraman ES, Lucito R, Wigler M: Circular binary segmentation for the analysis of array-based DNA copy number data. Biostatistics 2004, 5:557-72.

53. Sealfon RS, Hibbs MA, Huttenhower C, Myers CL, Troyanskaya OG: GOLEM: an interactive graph-based gene-ontology navigation and analysis tool. BMC Bioinformatics 2006, 7:443.

54. Peters AF, Scornet D, Müller DG, Kloareg B, Cock JM: Inheritance of organelles in artificial hybrids of the isogamous multicellular chromist alga Ectocarpus siliculosus (Phaeophyceae). Eur J Phycol 2004, 39:235-242.

doi:10.1186/1471-2199-12-2

Cite this article as: Dittami et al: Microarray estimation of genomic inter-strain variability in the genus Ectocarpus (Phaeophyceae). BMC Molecular Biology 2011 12:2.

\section{Submit your next manuscript to BioMed Central and take full advantage of:}

- Convenient online submission

- Thorough peer review

- No space constraints or color figure charges

- Immediate publication on acceptance

- Inclusion in PubMed, CAS, Scopus and Google Scholar

- Research which is freely available for redistribution

Submit your manuscript at www.biomedcentral.com/submit
C Biomed Central 